\title{
Synthesis and Characterization of $\mathbf{P b}\left(\mathrm{Zr}_{0.53}, \mathrm{Ti}_{0.47}\right) \mathbf{O}_{3}-\mathbf{P b}\left(\mathrm{Nb}_{1 / 3}, \mathrm{Zn}_{2 / 3}\right) \mathbf{O}_{3}$ Thin Film Cantilevers for Energy Harvesting Applications
}

\author{
E. M. A. Fuentes-Fernandez, ${ }^{1}$ W. Debray-Mechtaly, ${ }^{1}$ M. A. Quevedo-Lopez, ${ }^{1}$ B. Gnade, ${ }^{1}$ \\ E. Leon-Salguero, ${ }^{2}$ P. Shah, ${ }^{3}$ and H. N. Alshareef ${ }^{4}$ \\ ${ }^{1}$ Department of Materials Science and Engineering, University of Texas at Dallas, 800 W. Campbell Road, Richardson, \\ TX 75080, USA \\ ${ }^{2}$ Department of Materials Science, Research Center for Advanced Materials, 120 Avenue Miguel de Cervantes, \\ Chihuahua 31109, CHIH, Mexico \\ ${ }^{3}$ Materials Science, Texas MicroPower Inc., 7920 Beltline Road, Suite 1005, Dallas, TX 75254, USA \\ ${ }^{4}$ Department of Materials Science and Engineering, King Abdullah University of Science and Technology, Thuwal 23955, Saudi Arabia
}

Correspondence should be addressed to B. Gnade, gnade@utdallas.edu

Received 16 December 2011; Accepted 18 January 2012

Academic Editor: Ma Jan

Copyright (C) 2012 E. M. A. Fuentes-Fernandez et al. This is an open access article distributed under the Creative Commons Attribution License, which permits unrestricted use, distribution, and reproduction in any medium, provided the original work is properly cited.

\begin{abstract}
A complete analysis of the morphology, crystallographic orientation, and resulting electrical properties of $\mathrm{Pb}\left(\mathrm{Zr}_{0.53}, \mathrm{Ti}_{0.47}\right) \mathrm{O}_{3^{-}}$ $\mathrm{Pb}\left(\mathrm{Nb}_{1 / 3}, \mathrm{Zn}_{2 / 3}\right) \mathrm{O}_{3}$ (PZT-PZN) thin films, as well as the electrical behavior when integrated in a cantilever for energy harvesting applications, is presented. The PZT-PZN films were deposited using sol-gel methods. We report that using $20 \%$ excess $\mathrm{Pb}$, a nucleation layer of $\mathrm{PbTiO}_{3}(\mathrm{PT})$, and a fast ramp rate provides large grains, as well as denser films. The PZT-PZN is deposited on a stack of $\mathrm{TiO}_{2} / \mathrm{PECVD} \mathrm{SiO}_{2} / \mathrm{Si}_{3} \mathrm{~N}_{4} /$ thermal $\mathrm{SiO}_{2} / \mathrm{Poly}-\mathrm{Si} / \mathrm{Si}$. This stack is designed to allow wet-etching the poly-Si layer to release the cantilever structures. It was also found that the introduction of the poly-Si layer results in larger grains in the PZT-PZN film. PZT-PZN films with a dielectric constant of 3200 and maximum polarization of $30 \mu \mathrm{C} / \mathrm{cm}^{2}$ were obtained. The fabricated cantilever devices produced $\sim 300-400 \mathrm{mV}$ peak-to-peak depending on the cantilever design. Experimental results are compared with simulations.
\end{abstract}

\section{Introduction}

The ability to retrofit systems with power consuming electronics without having to consider issues associated with providing an independent power source offers a significant advantage for devices in hard to reach locations [1].

In the past few years there has been an increase in research on small wireless electronic devices [1-3]. Mechanical vibrations have received attention as a potential source of power for sensors and wireless electronics in a wide variety of applications [4]. To accomplish this, improving the piezoelectric material used in the cantilever is of paramount importance [5].

Piezoelectric materials are widely used for various devices, including multilayer capacitors, sensors, and actuators
$[2,3,6]$. By the 1950s, the ferroelectric solid solution $\mathrm{Pb}\left(\mathrm{Zr}_{1-x} \mathrm{Ti}_{x}\right) \mathrm{O}_{3}(\mathrm{PZT})$ was found to have exceptionally high dielectric and piezoelectric properties for compositions close to the morphotrophic phase boundary (MPB) $[7,8]$.

Research to improve the PZT properties, from the material and electrical standpoint, has been mainly accomplished by doping conventional PZT with different elements to "relax" the material $[5,9]$. Previous investigations on the dielectric and electrical properties of many ceramic systems, such as barium titanate (BT), lead zirconate titanate (PZT), lead magnesium niobate (PMN), lead titanate (PT), PMN-PT, PZT-BT, and PMN-PZT have demonstrated the importance of the subject [10-13]. Recently, there has been a great deal of interest in the lead zirconate titanatelead zinc niobate $\mathrm{Pb}\left(\mathrm{Zr}_{0.53} \mathrm{Ti}_{0.47}\right) \mathrm{O}_{3}-\mathrm{Pb}\left(\mathrm{Zn}_{1 / 3} \mathrm{Nb}_{2 / 3}\right) \mathrm{O}_{3}$ or 


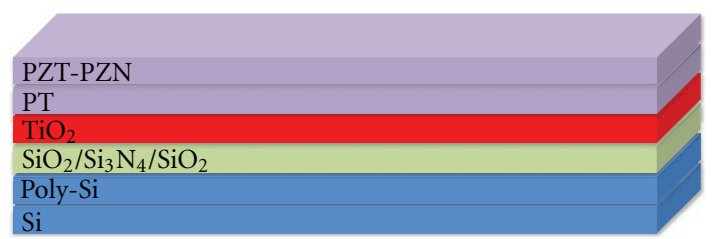

Figure 1: Schematic cross-section of PZT-PZN thin film on the cantilever stack.

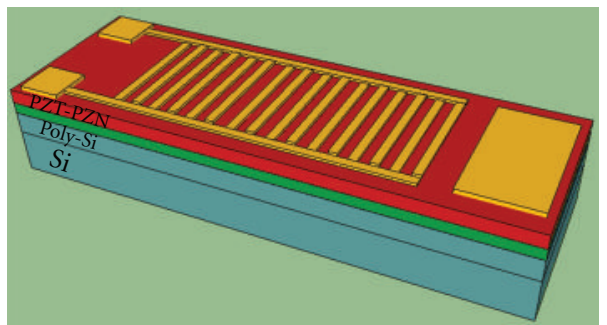

(a)

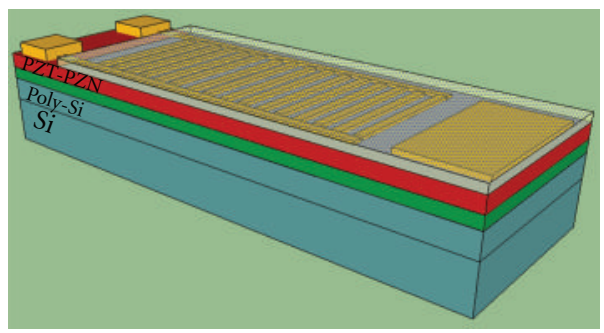

(c)

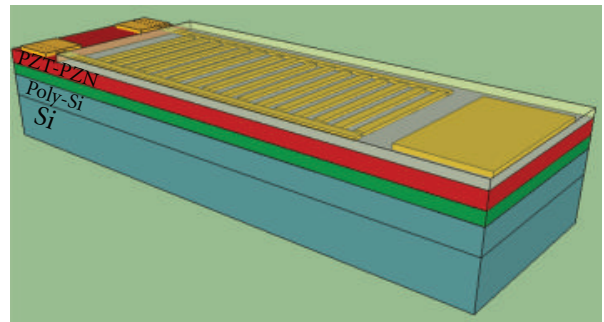

(b)

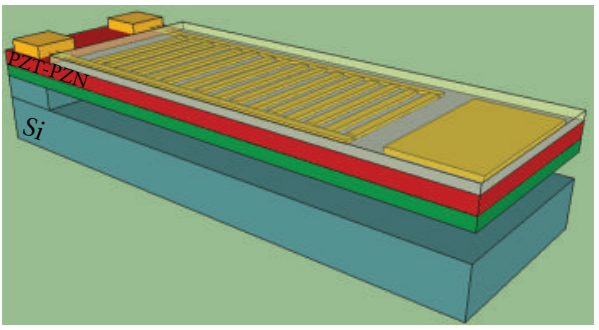

(d)

FIGURE 2: Schematics showing the cross-section of the PZT-PZN thin film stack subjected to the 4-step photolithography process, (a) metal deposition ( $50 \mathrm{~nm} \mathrm{Cr} / 500 \mathrm{~nm} \mathrm{Au}$ ), (b) $\mathrm{PECVD} \mathrm{SiO}_{2}$ encapsulation, (c) deposition of $50 \mathrm{~nm} \mathrm{Cr} / 500 \mathrm{~nm}$ Au for packaging-bonding, and (d) release step. The cantilever is operating in the $\mathrm{d}_{33}$ mode.

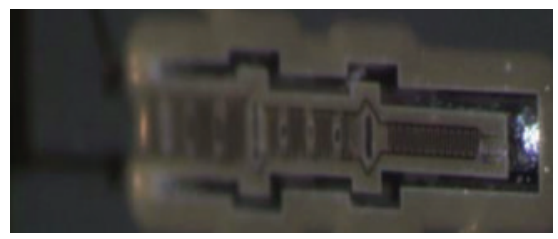

(a)

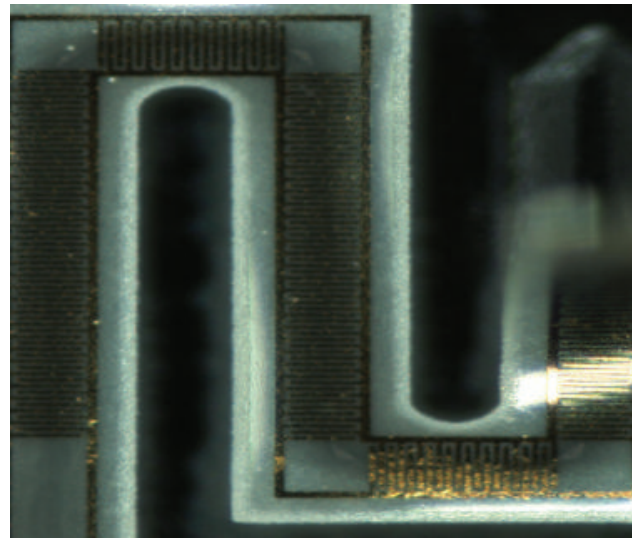

(c)

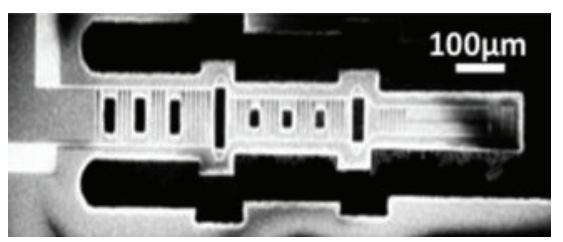

(b)

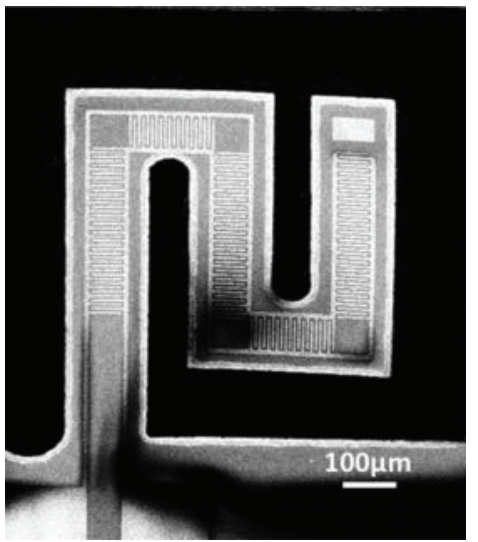

(d)

FIGURE 3: Optical micrographs and SEM pictures of; (a) and (b) "linear-shaped" cantilever, respectively, and (c) and (d) "snake-shaped" cantilever. 


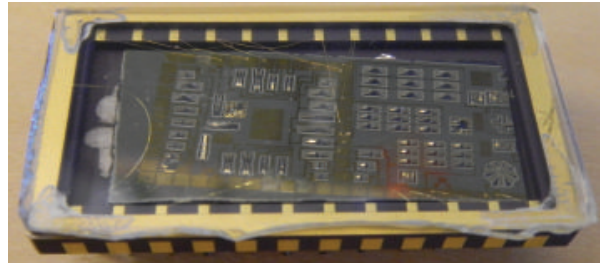

(a)

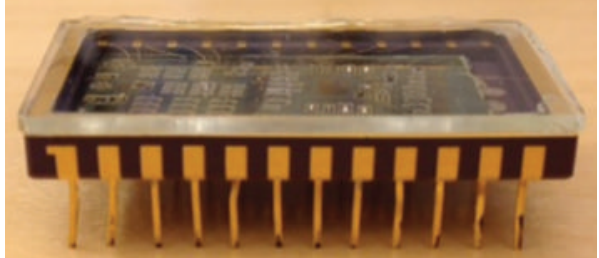

(b)

Figure 4: Micrographs of the cantilever device mounted and wire-bonded to the chip carrier.

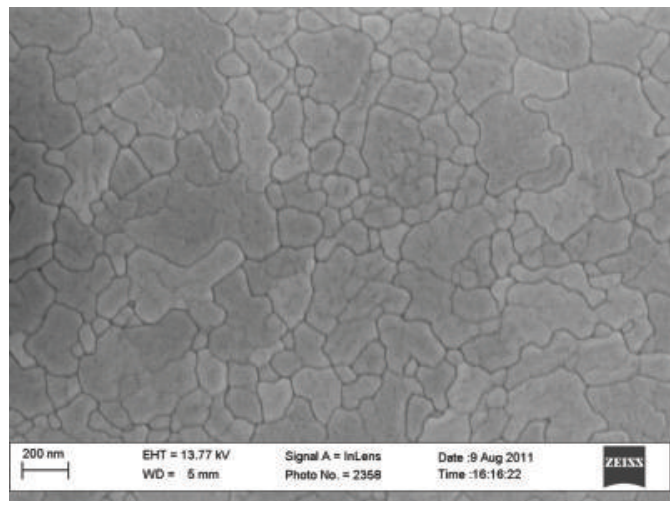

(a)

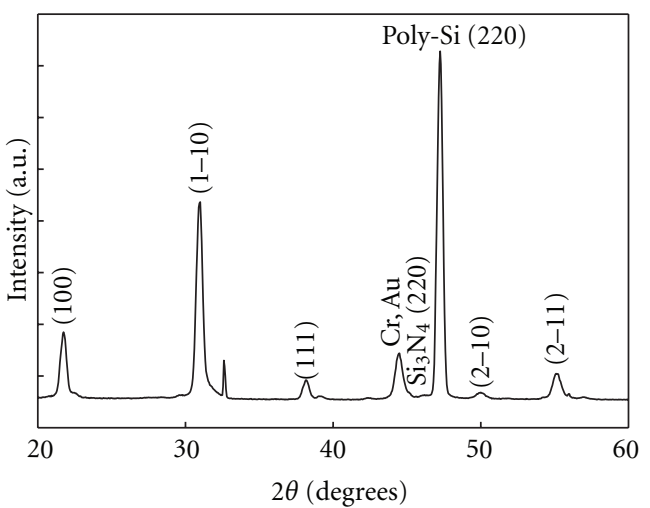

(b)

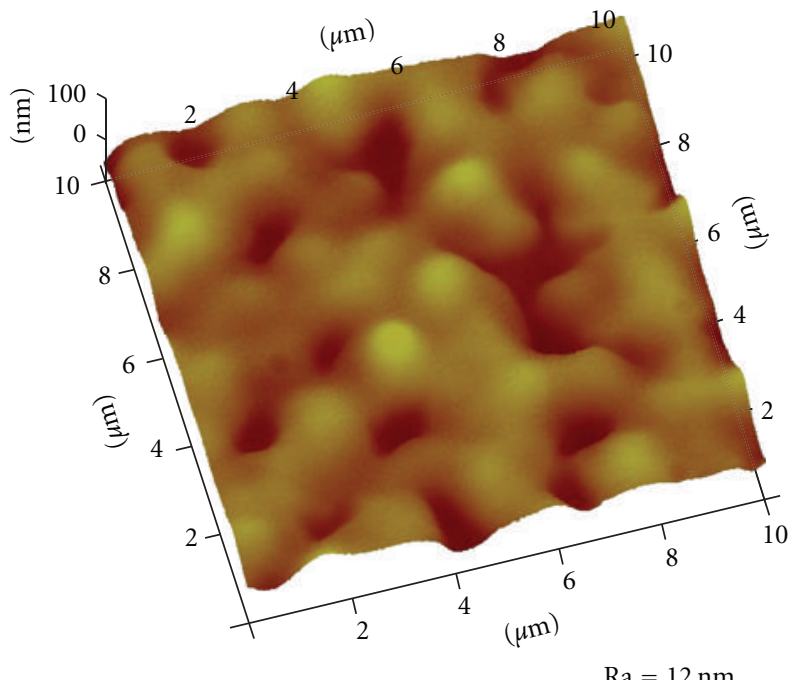

(c)

FIgURE 5: (a) SEM picture showing a dense PZT-PZN film with large grain size using optimum conditions (20\% excess Pd, fast ramp rate, and PT nucleation layer), (b) X-ray diffraction pattern of the PZT-PZN film on the cantilever stack, and (c) AFM image of the PZT-PZN thin film on the cantilever stack having a roughness of $12 \mathrm{~nm}$, due to the poly-Si layer needed for wet-etch processing.

(PZT-PZN) system because of its high dielectric, piezoelectric, and ferroelectric properties [14-16]. It is important to have not only a good material, but also a device design that matches the material properties. For this reason, the search for different device designs is of great interest. The cantilever structure is the most efficient structure that has been reported to date $[2,4]$.

In this paper, the synthesis and characterization of the PZT-PZN thin films for energy harvesting applications are presented. The films were subsequently integrated using 


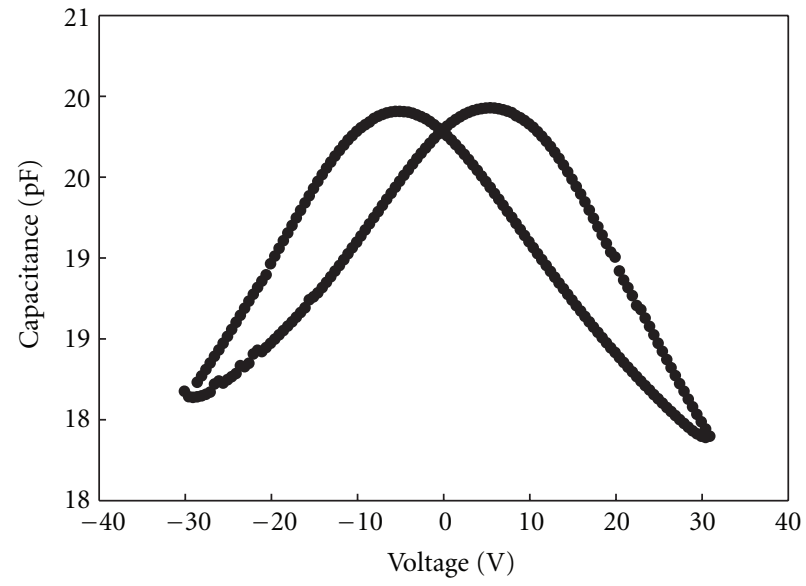

(a)

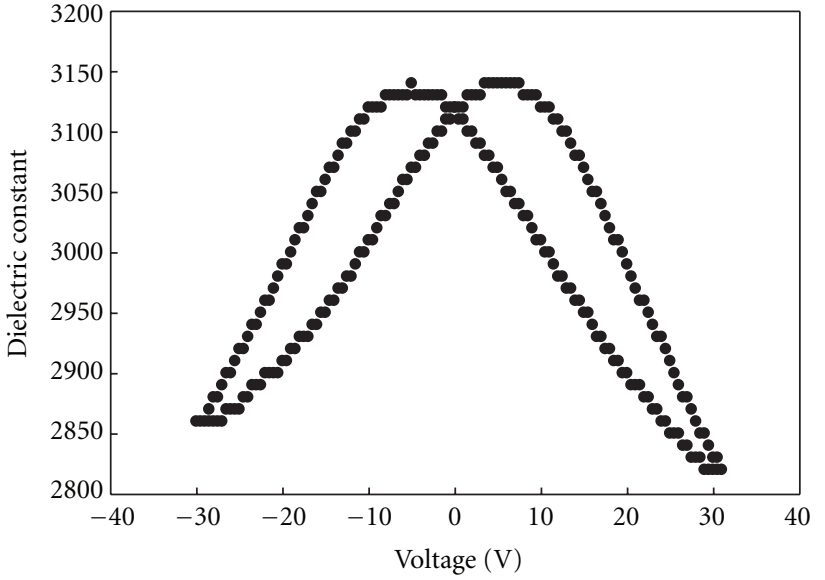

(b)

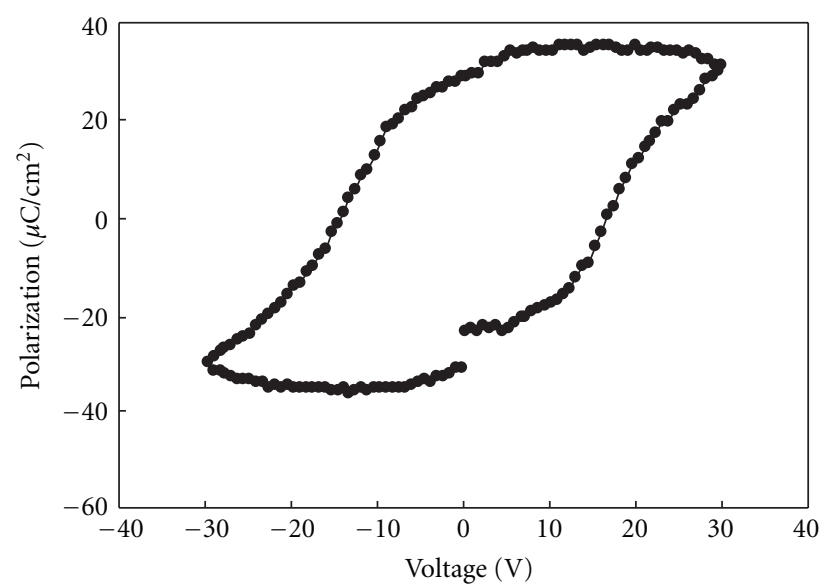

(c)

Figure 6: Electrical characterization of the PZT-PZN film on the released cantilever. (a) Capacitance versus Voltage curve, (b) calculated dielectric constant versus voltage curve, and (c) polarization versus voltage hysteresis curve.

silicon-compatible microfabrication techniques to fabricate cantilevers using a wet-etch release process.

Additionally, packaging and electrical characterization such as capacitance, polarization, and dielectric constant versus voltage were performed. Experimental voltage output at the resonance frequencies of the cantilevers is compared with simulations.

\section{Experimental}

The solutions used for the fabrication of PZT-PZN films were prepared using a sol-gel process that we previously described for $\mathrm{Pb}\left(\mathrm{Zr}_{1-x}, \mathrm{Ti}_{x}\right) \mathrm{O}_{3}[17,18]$. The starting precursors, zirconium (IV) butoxide, titanium (IV) isopropoxide, and niobium (V) ethoxide, were reacted in acetic acid (95\%) and methanol. Lead (IV) acetate and zinc acetate dihydrate were added, and the solution was heated to $85^{\circ} \mathrm{C}$ to dissolve the acetates. The final PZT-PZN solution has a concentration of $0.4 \mathrm{M}$. A nucleation $\mathrm{PbTiO}_{3}$ (PT) layer was also prepared in a similar manner, but with using titanium (IV) isopropoxide and lead (IV) acetate. The $\mathrm{Pb}_{1.2}\left(\mathrm{Zr}_{0.53}, \mathrm{Ti}_{0.47}\right) \mathrm{O}_{3}$ $\mathrm{Pb}\left(\mathrm{Zn}_{1 / 3}, \mathrm{Nb}_{2 / 3}\right) \mathrm{O}_{3}$ films were deposited from the solution using a spin-coating technique at $3000 \mathrm{rpm}$ for $30 \mathrm{~s}$, followed by a soft bake on a hot plate at $300^{\circ} \mathrm{C}$ for $10 \mathrm{~min}$ to evaporate the solvents. Finally, the crystallization step is done at $675^{\circ} \mathrm{C}$ for $30 \mathrm{~min}$ in a tube furnace in an air atmosphere, as previously described [9].

The PZT-PZN polycrystalline thin film was grown on a stack consisting of $3 \mu \mathrm{m}$ of poly-Si, $100 \mathrm{~nm}$ of thermal $\mathrm{SiO}_{2}$ and $350 \mathrm{~nm}$ of $\mathrm{Si}_{3} \mathrm{~N}_{4}$ deposited using LPCVD, $500 \mathrm{~nm}$ of PECVD $\mathrm{SiO}_{2}$ and $50 \mathrm{~nm}$ of sputtered Ti (Figure 1). The entire stack is annealed at $1000^{\circ} \mathrm{C}$ for $30 \mathrm{~min}$ in $\mathrm{O}_{2}$ to completely oxidize the Ti to $\mathrm{TiO}_{2}$. Next, the stack is subjected to a 4-step photolithography process to fabricate the cantilevers. The first step is the metallization shown in Figure 2(a). The second step is the encapsulation of the device with $100 \mathrm{~nm}$ of PECVD $\mathrm{SiO}_{2}$, Figure 2(b); the third step is the deposition of $50 \mathrm{~nm} \mathrm{Cr} / 500 \mathrm{~nm} \mathrm{Au}$ for packaging-bonding purposes, shown schematically in Figure 2(c). Finally the fourth step is the release of the cantilever as shown in Figure 2(d). The release is carried out using 20\% HF to etch the PZT-PZN, $\mathrm{TiO}_{2}$ and $\mathrm{SiO}_{2}$ layers. Next, a RIE plasma-etch step is used to remove the $\mathrm{Si}_{3} \mathrm{~N}_{4}$ and the poly-Si layer is etched using 20\% $\mathrm{KOH}$ at $50^{\circ} \mathrm{C}$. This last step releases the cantilever. Images 


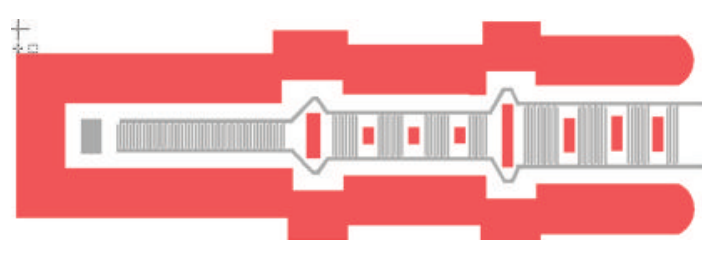

(a)

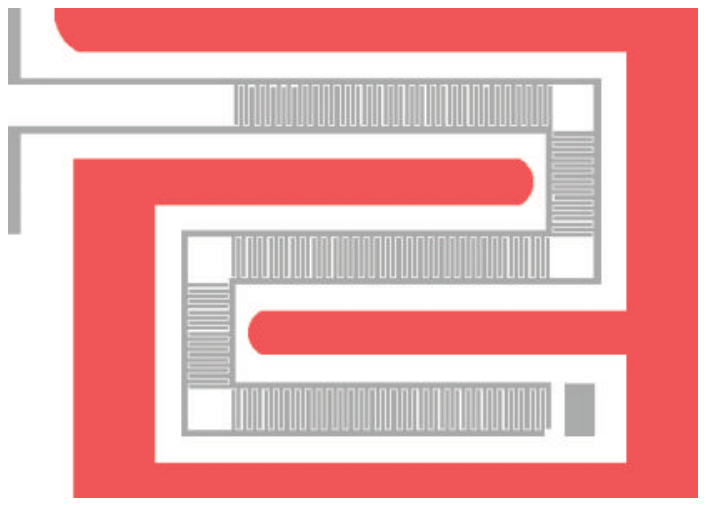

(c)

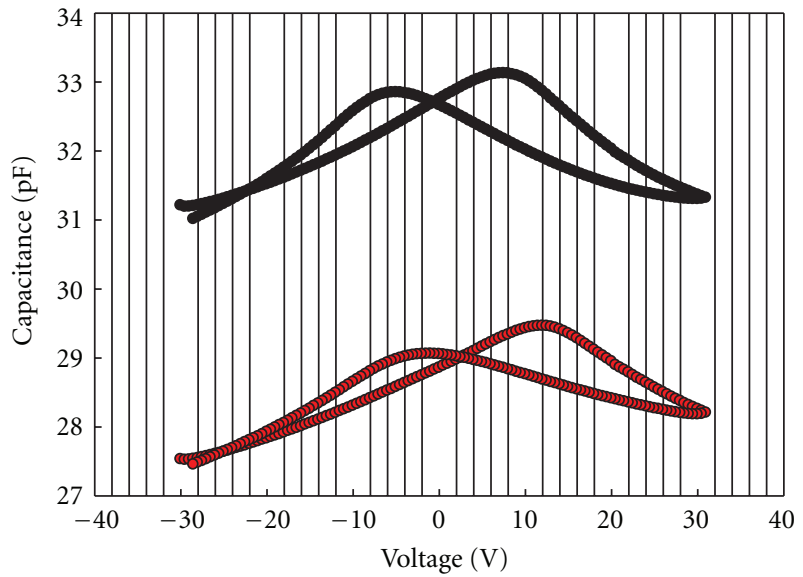

- After bonding

- After poling

(b)

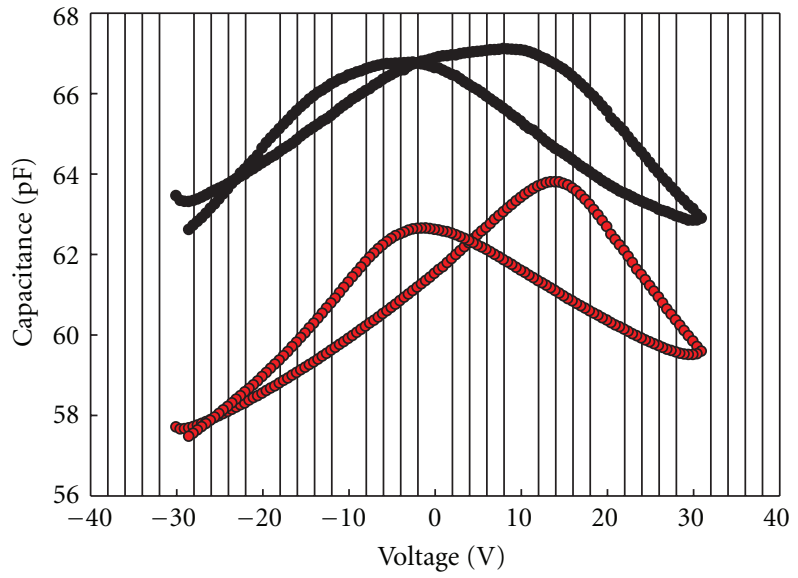

- After bonding

- After poling

(d)

FIGURE 7: (a) Schematic of the "linear-shaped" cantilever, (b) C-V curves of the cantilever device mounted on the chip carrier, showing the results before and after poling. (c) Schematic of the "snake-shaped" cantilever, (d) C-V curves of the cantilever device mounted on the chip carrier, showing the results before and after poling.

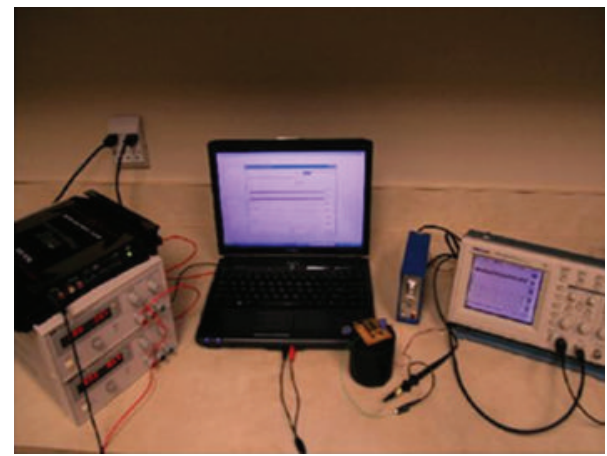

FIGURE 8: Picture of the shaker setup used to measure the voltage-output from the cantilever device. 


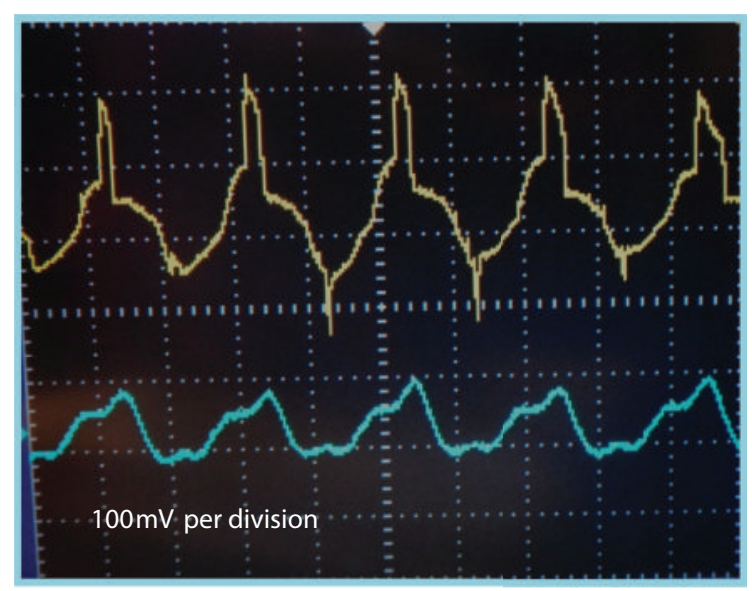

(a)

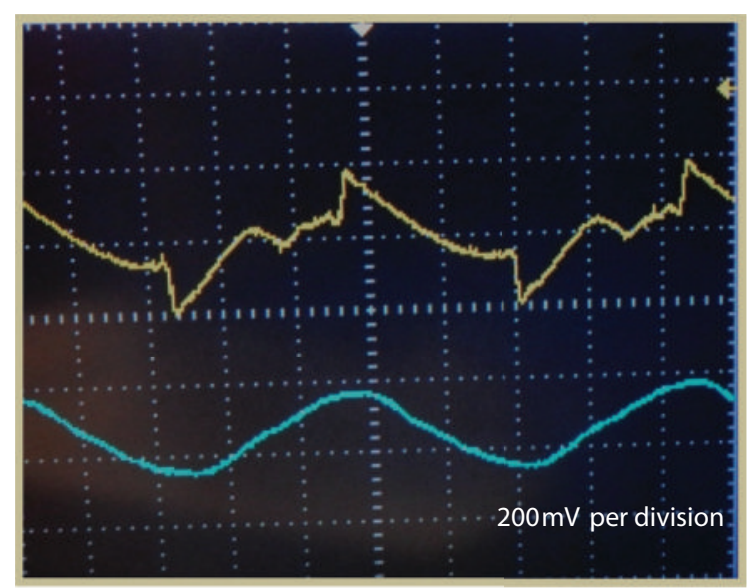

(d)

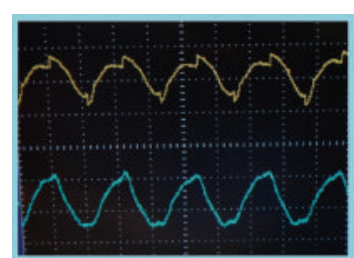

(b)

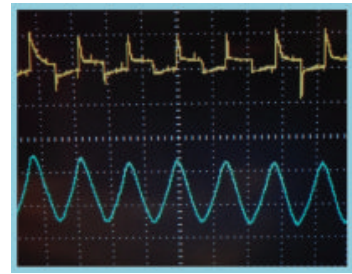

(c)

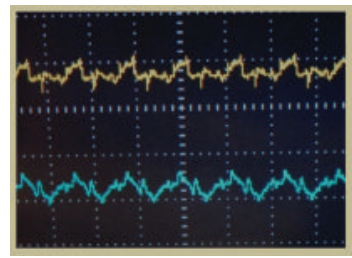

(e)

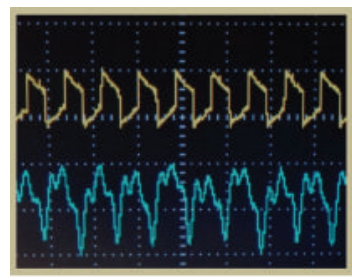

(f)

Figure 9: Oscilloscope images showing the voltage-output of (a) "linear-shaped" cantilever at its resonance frequency (960 Hz), (b) same structure but at a frequency below the resonance frequency $(869 \mathrm{~Hz}),(\mathrm{c})$ same "linear-shaped" structure at a frequency above the resonance frequency $(1400 \mathrm{~Hz}),(\mathrm{d})$ "snake-shaped" cantilever at resonance frequency $(875 \mathrm{~Hz}),(\mathrm{e})$ same structure at a frequency below the resonance frequency $(800 \mathrm{~Hz})$, and (f) same "snake-shaped" structure at a frequency above the resonance frequency $(1200 \mathrm{~Hz})$. The yellow signal, or top trace, is the voltage output from the cantilever, and the blue signal, or bottom trace, is the frequency sensor output signal showing the time correlation between the shaker and the cantilever.

of the resulting cantilevers are shown in Figure 3, where (a) and (c) are optical microscopic images of two different cantilever designs, and Figures $3(\mathrm{~b})$ and $3(\mathrm{~d})$ are SEM micrographs of the same cantilever designs. The released cantilevers were mounted and wire-bonded to a chip carrier for poling and output voltage measurements, as show in Figure 4 .

\section{Results and Discussion}

3.1. Material Characterization. The deposition of PZTPZN films on the $\mathrm{TiO}_{2}$ buffer layer was optimized by varying the lead content, ramp rate, and insertion of a nucleation layer between the film and the underlying $\mathrm{TiO}_{2}$, as shown in Figure 1. Optimum conditions were $20 \%$ excess of $\mathrm{Pb}$, direct sample insertion into the furnace previously heated to $675^{\circ} \mathrm{C}$ using what we call "a fast ramp rate" (a few seconds to insert the samples manually into the preheated furnace), and the use of a $\mathrm{PbTiO}_{3}(\mathrm{PT})$ nucleation layer between $\mathrm{TiO}_{2}$ and the PZT-PZN [9, 19, $20]$.

SEM results shown in Figure 5(a) indicate a dense film and large grains size $(150 \mathrm{~nm})$, which is a difficult characteristic to achieve in PZT-PZN thin films, but is essential for optimal electrical performance. A typical XRD diffraction pattern for the PZT-PZN is shown in Figure 5(b). $\mathrm{XRD}$ results demonstrate the absence of pyrochlore, but show a preferred perovskite orientation in the (110) plane.

AFM results (Figure 5(c)) show that the average roughness of the PZT-PZN films is $12 \mathrm{~nm}$. The increased roughness is due to the poly-Si layer. However, the poly-Si layer is required for the wet-etch release of the cantilever. The results using the optimum conditions could be understood as a competition between two effects: lead loss and perovskite phase crystallization [9].

3.2. Electrical Characterization. The electrical characterization of the PZT-PZN thin film was done using interdigitated 
Volume: Von Mises stress (GPa)

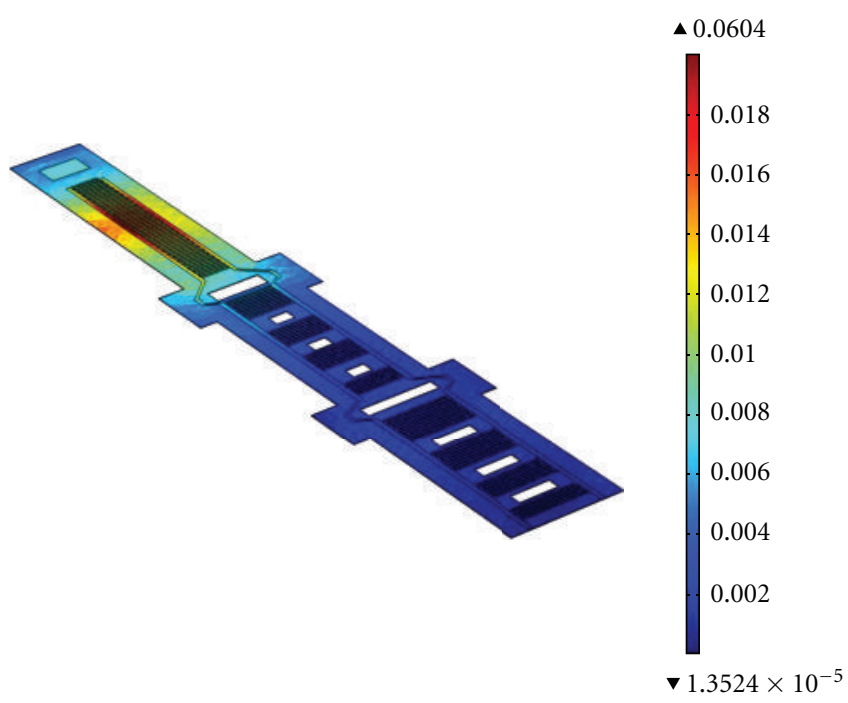

Surface: Von Mises stress (GPa)

Surface deformation: Displacement field (material)

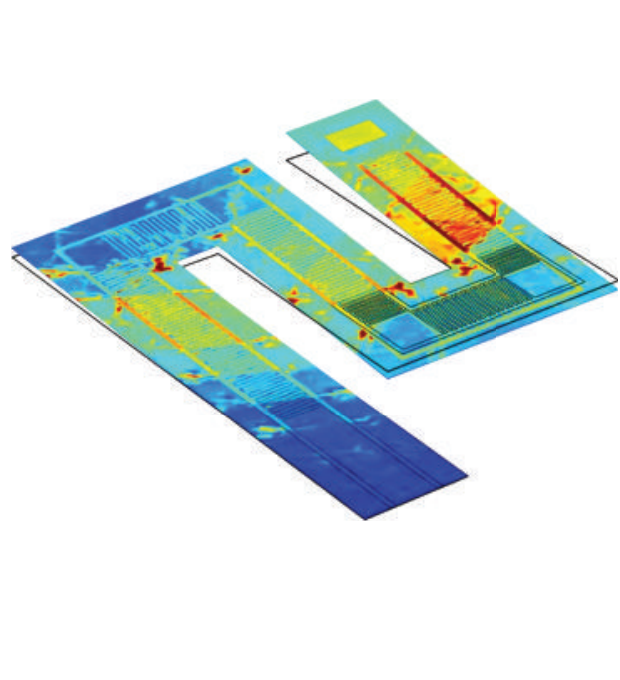

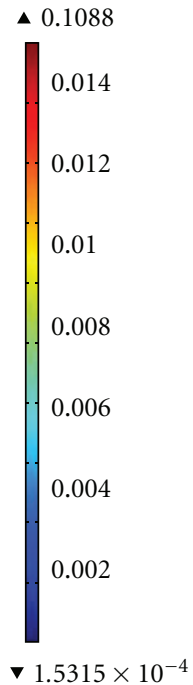

(a)

(b)

FIGURE 10: Simulation images based on the finite element method (FEM) (COMSOL package) showing the areas of highest stress in the film of (a) "linear-shaped" cantilever and (b) "snake-shaped" cantilever.

electrodes (IDE) on the released cantilevers. Capacitance versus voltage $(\mathrm{C}-\mathrm{V})$ measurements were performed on the PZT-PZN films to calculate the dielectric constant. C$\mathrm{V}$ results are shown in Figure 6(a), where the maximum capacitance $(20 \mathrm{pF})$ is observed at $5 \mathrm{~V}$. The calculated dielectric constant for PZT-PZN is shown in Figure 6(b). These calculations were based on studies previously reported [21, 22]. The maximum dielectric constant calculated was 3200 at $5 \mathrm{~V}$. Polarization measurements were also performed on the relaxor thin film and the results are shown in Figure $6(\mathrm{c})$. The films show a maximum polarization value of $31.2 \mu \mathrm{C} / \mathrm{cm}^{2}$ and a remnant polarization of $28.5 \mu \mathrm{C} / \mathrm{cm}^{2}$.

It is well known that a larger grain size can improve the dielectric constant of perovskite materials [23]. Therefore, the high dielectric constant and polarization results are attributed to the larger grain size observed in the PZT-PZN thin films.

In order to measure the output voltage due to vibrational excitation, the films were exposed to a poling step. The poling is accomplished by applying an electric field across the material at elevated temperatures; for thin films, longer poling times are typically required compared to bulk ceramics $[24,25]$.

The poling was performed after mounting and wirebonding the devices to a chip carrier, as shown in Figure 4. The poling conditions were $200 \mathrm{kV} / \mathrm{cm}$ at $200^{\circ} \mathrm{C}$ for $50 \mathrm{~min}$. $\mathrm{C}-\mathrm{V}$ measurements before and after poling are shown in Figure 7. Two device structures are shown in this figure, "linear-shaped" (Figure 7(a)) and "snake-shaped" (Figure 7(c)) cantilevers. C-V results from both cantilevers increased after wire bonding because of an increase in contact area. If we compare both $\mathrm{C}-\mathrm{V}$ measurements, we find that the capacitance for the "snake-shaped" cantilever is higher than for the "linear-shaped" cantilever. This may be explained because the contact area is higher in the "snakedshape" cantilever.

The C-V curve after poling shifted by an average of $5 \mathrm{~V}$ from the original position, as show in Figures 7 (b) and 7(d).

The cantilevers were subsequently tested by mounting the packaged device to a mechanical shaker (Bruel and Kjaer Instruments Inc. Model Type 4810). The force generated by the shaker is proportional to the acceleration, which is controlled by the applied voltage to a power amplifier (Pyle PLA2200). The amplifier was driven by a $12-\mathrm{V}$ power supply and signals from the PC frequency generator. The output voltage from the cantilever was monitored using a Tektronix digital oscilloscope (TDS 210), as shown in Figure 8.

Voltage-output results for the two cantilever designs shown in Figure 7 are presented in Figure 9, where (a) is for the "linear-shaped" $2000 \mu \mathrm{m}$ long cantilever, and (b) is for the "snake-shaped" cantilever. The "snake-shaped" cantilever shows an output voltage value of $400 \mathrm{mV}$ peakto-peak while the "linear-shaped" cantilever shows a $300 \mathrm{mV}$ p-p output voltage at the resonant frequencies of $875 \mathrm{~Hz}$ and $960 \mathrm{~Hz}$, respectively. The differences are consistent with simulation-based results using the finite element method (FEM). The results shown in Figure 10 show that for the "linear-shaped" cantilever (a), the area of highest stress is near the tip area, while for the "snake-shaped" cantilever (b), there is more stress distributed across the structure.

The FEM (COMSOL) package was used also to model the structural deformation and the voltage output at the resonant frequency, as determined from experimental analysis of the tested cantilevers. Results are shown in Figure 11, where (a) and (c) are the results of the simulated deformation at the respective resonant frequencies; for the "linear-shaped" cantilever a deformation of $104.6 \mu \mathrm{m}$ at $960 \mathrm{~Hz}$ and $47.1 \mu \mathrm{m}$ at $875 \mathrm{~Hz}$ for the "snake-shaped" cantilever. 


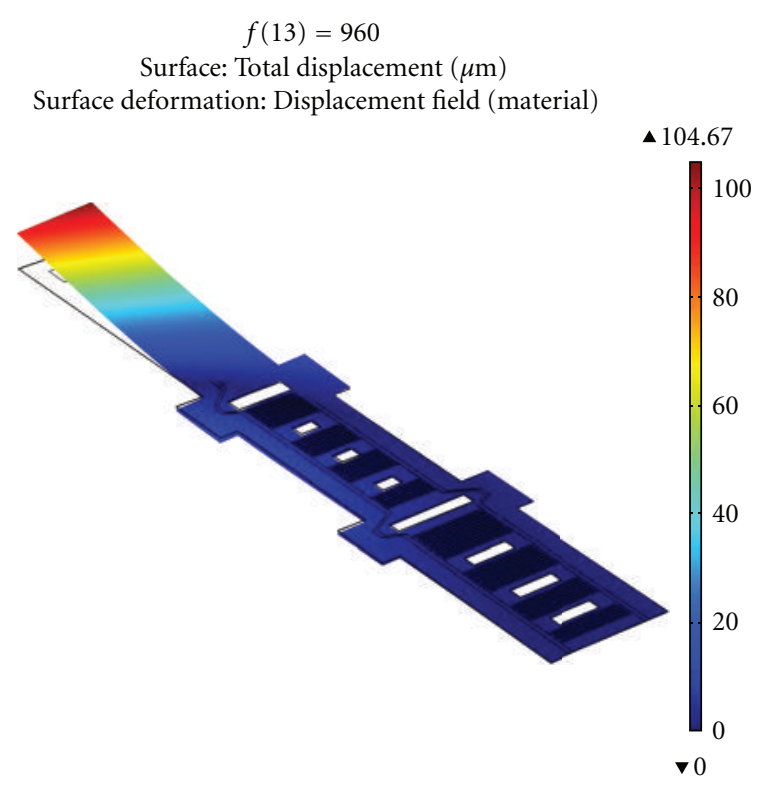

(a)

$$
f(1)=875
$$

Volume: Total displacement $(\mu \mathrm{m})$

Volume deformation: Displacement field (material)

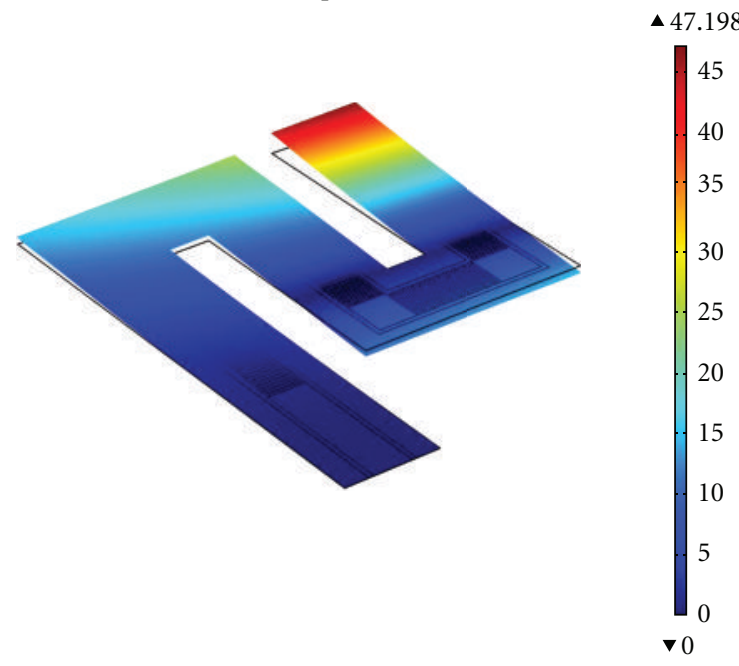

(c)

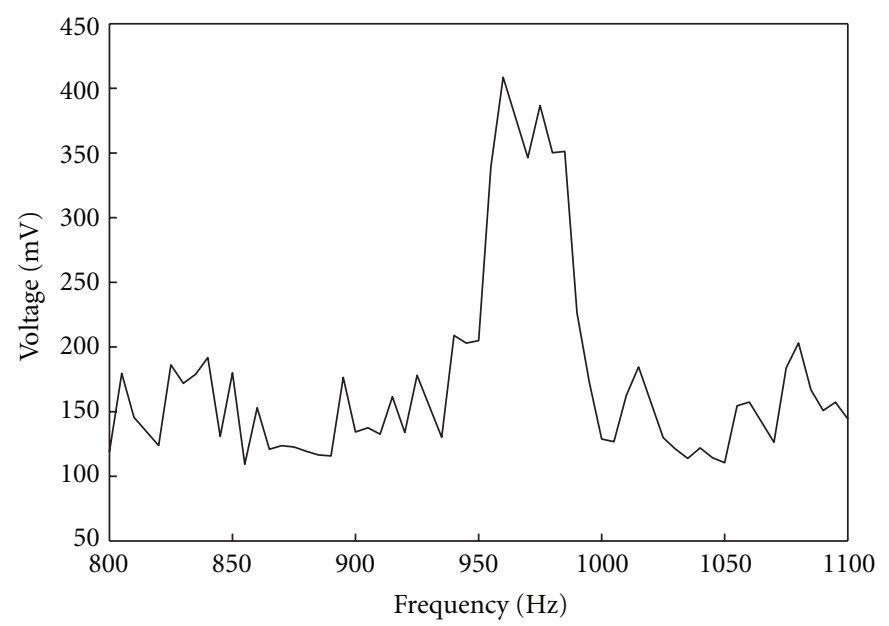

(b)

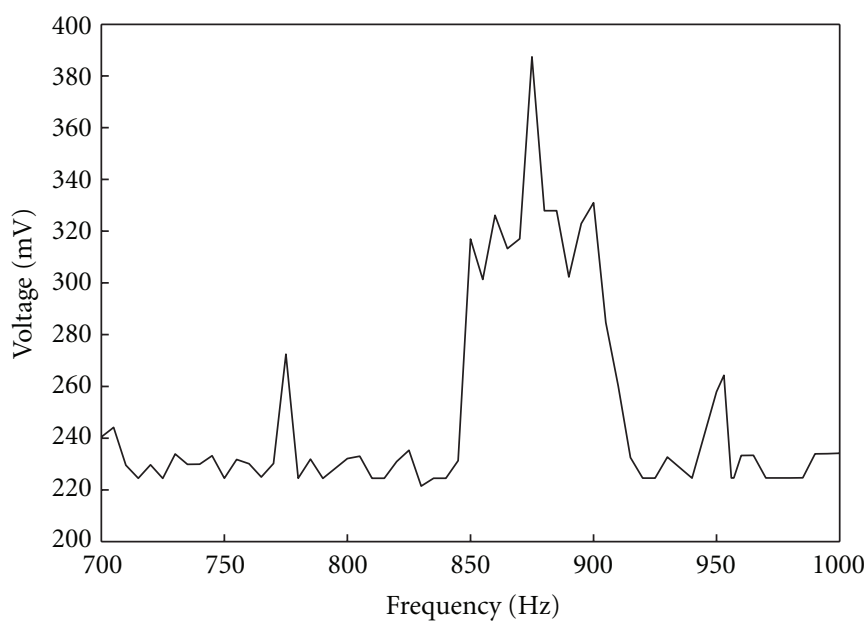

(d)

FIGURE 11: Simulation results using the finite element method (FEM), (COMSOL package). (a) Schematic showing the deformation of the "linear-shaped" cantilever, (b) simulated voltage versus frequency plot for the "linear-shape" cantilever, (c) Schematic showing the deformation of the "snake-shaped" cantilever, and (d) simulated voltage versus frequency plot for the "snake-shaped" cantilever.

For the "linear-shaped" cantilever the experimental results show an output voltage of $300 \mathrm{mV}$ over a range of frequencies of 983 to $1053 \mathrm{~Hz}$. Comparing this result to the simulation shown in Figure 10(b), we find that there is a $2 \%$ of difference between the experimental and calculated results. For the "snake-shaped" cantilever the experimental result showed a maximum voltage of $400 \mathrm{mV}$ from 858 to $890 \mathrm{~Hz}$ with a difference of $2 \%$ between the simulated and experimental results, as shown in Figure 11(d). We believe that the voltage output can be improved by adding a weight at the end of the cantilever to reduce the resonant frequency and improve the deflection of the cantilevers, and consequently increase the voltage output [26].

\section{Conclusions}

PZT-PZN thin film and microcantilever fabrication processes have been developed to harvest vibrational energy. Integrated cantilevers were successfully fabricated using a wet-etch process to release the cantilevers. The properties of 
the relaxor films were optimized to yield the desired phase on the cantilever devices. A dielectric constant of 3200 and polarization of $30 \mu \mathrm{C} / \mathrm{cm}^{2}$ were obtained. A 300 to $400 \mathrm{mV}$ p-p output voltage, depending on the cantilever design tested, was obtained. Simulations are in good agreement with experimental data.

\section{Acknowledgments}

The authors would like to thank to NSF Phase I SBIR grant and the Texas Emerging Technology Fund for partial financial support.

\section{References}

[1] S. P. Beeby, M. J. Tudor, and N. M. White, "Energy harvesting vibration sources for microsystems applications," Measurement Science and Technology, vol. 17, no. 12, article R01, pp. R175-R195, 2006.

[2] S. Roundy, P. K. Wright, and J. Rabaey, "A study of low level vibrations as a power source for wireless sensor nodes," Computer Communications, vol. 26, no. 11, pp. 1131-1144, 2003.

[3] S. Roundy and P. K. Wright, "A piezoelectric vibration based generator for wireless electronics," Smart Materials and Structures, vol. 13, no. 5, pp. 1131-1142, 2004.

[4] A. Hajati and S.-G. Kim, "Ultra-wide bandwidth piezoelectric energy harvesting," Applied Physics Letters, vol. 99, no. 8, Article ID 083105, 2011.

[5] R. Yimnirun, N. Triamnak, M. Unruan, A. Ngamjarurojana, Y. Laosiritaworn, and S. Ananta, "Ferroelectric properties of $\mathrm{Pb}\left(\mathrm{Zr}_{1 / 2} \mathrm{Ti}_{1 / 2}\right) \mathrm{O}_{3}-\mathrm{Pb}\left(\mathrm{Zn}_{1 / 3} \mathrm{Nb}_{2 / 3}\right) \mathrm{O}_{3}$ ceramics under compressive stress," Current Applied Physics, vol. 9, no. 1, pp. 249-252, 2009.

[6] N. M. White and J. D. Turner, "Thick-film sensors: past, present and future," Measurement Science and Technology, vol. 8, no. 1, pp. 1-20, 1997.

[7] A. J. Bell, "Factors influencing the piezoelectric behaviour of PZT and other "morphotropic phase boundary" ferroelectrics," Journal of Materials Science, vol. 41, no. 1, pp. 13-25, 2006.

[8] B. Jaffe, W. R. Cook, and H. Jaffe, Piezoelectric Ceramics, Academic Press, 1971.

[9] E. Fuentes-Fernandez, W. Debray-Mechtaly, M. A. Quevedo-Lopez et al., "Fabrication and characterization of $\mathrm{Pb}\left(\mathrm{Zr}_{0.53}, \mathrm{Ti}_{0.47}\right) \mathrm{O}_{3}-\mathrm{Pb}\left(\mathrm{Nb}_{1 / 3}, \mathrm{Zn}_{2 / 3}\right) \mathrm{O}_{3}$ thin films on cantilever stacks," Journal of Electronic Materials, vol. 40, no. 1, pp. 85-91, 2011.

[10] Q. M. Zhang, J. Zhao, K. Uchino, and J. Zheng, "Change of the weak-field properties of $\mathrm{Pb}(\mathrm{ZrTi}) \mathrm{O}_{3}$ piezoceramics with compressive uniaxial stresses and its links to the effect of dopants on the stability of the polarizations in the materials," Journal of Materials Research, vol. 12, no. 1, pp. 226-234, 1997.

[11] R. Yimnirun, S. Ananta, A. Ngamjarurojana, and S. Wongsaenmai, "Effects of uniaxial stress on dielectric properties of ferroelectric ceramics," Current Applied Physics, vol. 6, no. 3, pp. 520-524, 2006.

[12] G. Yang, S. F. Liu, W. Ren, and B. K. Mukherjee, "Uniaxial stress dependence of the piezoelectric properties of lead zirconate titanate ceramics," in Symposium on Smart Structures and Materials, vol. 3992 of Proceedings of the SPIE, pp. 103 113, June, 2000.
[13] R. Yimnirun, "Contributions of domain-related phenomena on dielectric constant of lead-based ferroelectric ceramics under uniaxial compressive pre-stress," International Journal of Modern Physics B, vol. 20, no. 23, pp. 3409-3417, 2006.

[14] N. Vittayakorn, G. Rujijanagul, T. Tunkasiri, X. Tan, and D. P. Cann, "Perovskite phase formation and ferroelectric properties of the lead nickel niobate-lead zinc niobatelead zirconate titanate ternary system," Journal of Materials Research, vol. 18, no. 12, pp. 2882-2889, 2003.

[15] H. Fan and H.-E. Kim, "Perovskite stabilization and electromechanical properties of polycrystalline lead zinc niobatelead zirconate titanate," Journal of Applied Physics, vol. 91, no. 1, pp. 317-322, 2002.

[16] N. Vittayakorn, G. Rujijanagul, X. Tan, H. He, M. A. Marquardt, and D. P. Cann, "Dielectric properties and morphotropic phase boundaries in the $x \mathrm{~Pb}\left(\mathrm{Zn}_{1 / 3} \mathrm{Nb}_{2 / 3}\right) \mathrm{O}_{3}-(1-$ $x) \mathrm{Pb}\left(\mathrm{Zr}_{0.5} \mathrm{Ti}_{0.5}\right) \mathrm{O}_{3}$ pseudo-binary system," Journal of Electroceramics, vol. 16, no. 2, pp. 141-149, 2006.

[17] T. Schneller and R. Waser, "Chemical modifications of $\mathrm{Pb}\left(\mathrm{Zr}_{0.3}, \mathrm{Ti}_{0.7}\right) \mathrm{O}_{3}$ precursor solutions and their influence on the morphological and electrical properties of the resulting thin films," Journal of Sol-Gel Science and Technology, vol. 42, no. 3, pp. 337-352, 2007.

[18] H. N. Al-Shareef, K. R. Bellur, O. Auciello, X. Chen, and A. I. Kingon, "Effect of composition and annealing conditions on the electrical properties of $\mathrm{Pb}\left(\mathrm{Zr}_{x} \mathrm{Ti}_{1-x}\right) \mathrm{O}_{3}$ thin films deposited by the sol-gel process," Thin Solid Films, vol. 252, no. 1, pp. 38-43, 1994.

[19] E. Fuentes-Fernandez, L. Baldenegro-Perez, M. QuevedoLopez et al., "Optimization of $\mathrm{Pb}\left(\mathrm{Zr}_{0.53}, \mathrm{Ti}_{0.47}\right) \mathrm{O}_{3}$ films for micropower generation using integrated cantilevers," SolidState Electronics, vol. 63, no. 1, pp. 89-93, 2011.

[20] L. A. Baldenegro-Perez, W. Debray-Mechtaly, E. FuentesFernandez et al., "Study on the microstructure and electrical properties of $\mathrm{Pb}\left(\mathrm{Zr}_{0.53}, \mathrm{Ti}_{0.47}\right) \mathrm{O}_{3}$ thin-films," Materials Science Forum, vol. 644, pp. 97-100, 2010.

[21] H. N. Al-Shareef, D. Dimos, M. V. Raymond, R. W. Schwartz, and C. H. Mueller, "Tunability and calculation of the dielectric constant of capacitor structures with interdigital electrodes," Journal of Electroceramics, vol. 1, no. 2, pp. 145-153, 1997.

[22] G. W. Farnell, I. A. Cermak, P. Silvester, and S. K. Wong, "Capacitance and field distributions for interdigital surfacewave transducers ," IEEE Transactions on Sonics and Ultrasonics, vol. 17, no. 3, pp. 188-195, 1970.

[23] G. Arlt, D. Hennings, and G. De With, "Dielectric properties of fine-grained barium titanate ceramics," Journal of Applied Physics, vol. 58, no. 4, pp. 1619-1625, 1985.

[24] G. Yi, Z. Wu, and M. Sayer, "Preparation of $\mathrm{Pb}(\mathrm{Zr}, \mathrm{Ti}) \mathrm{O}_{3}$ thin films by sol gel processing: electrical, optical, and electro-optic properties," Journal of Applied Physics, vol. 64, no. 5, pp. 27172724, 1988.

[25] S. Watanabe, T. Fujiu, and T. Fujii, "Effect of poling on piezoelectric properties of lead zirconate titanate thin films formed by sputtering," Applied Physics Letters, vol. 66, pp. 1481-1483, 1995.

[26] Q.-M. Wang, X.-H. Du, B. Xu, and L. Eric Cross, "Electromechanical coupling and output efficiency of piezoelectric bending actuators," IEEE Transactions on Ultrasonics, Ferroelectrics, and Frequency Control, vol. 46, no. 3, pp. 638-646, 1999. 

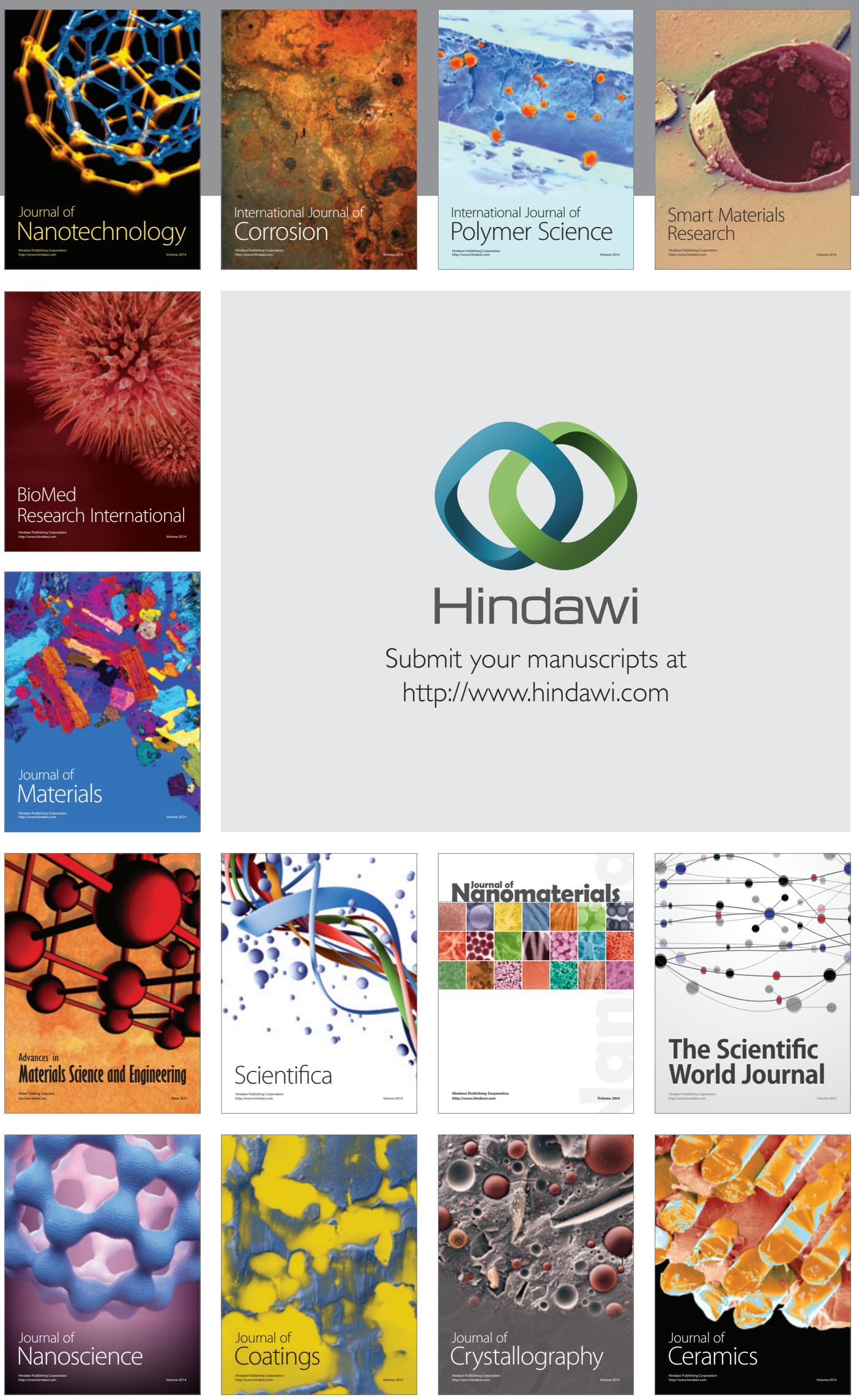

The Scientific World Journal

Submit your manuscripts at

http://www.hindawi.com

\section{World Journal}

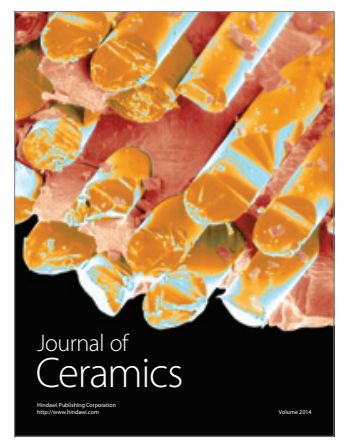

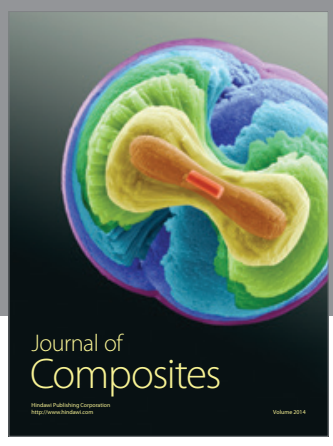
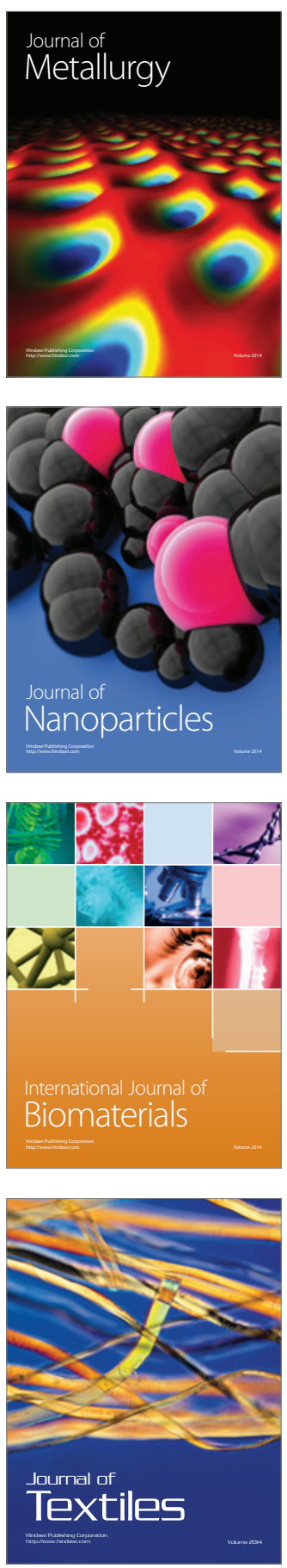